\title{
Genetically determined factors as predictors of radiological change in patients with early symmetrical arthritis
}

\author{
P Emery, M Salmon, H Bradley, P Wordsworth, E Tunn, P A Bacon, R Waring
}

\begin{abstract}
Objective-To determine whether genetic factors associated with established rheumatoid arthritis could, in combination with rheumatoid factor, predict the development of radiological erosions in patients with early symmetrical (rheumatoid-like) arthritis.
\end{abstract}

Design-Prospective study.

Setting-Teaching hospital, early arthritis clinic.

Subjects-Forty nine patients with symmetrical polyarthritis attending the early arthritis clinic.

Main outcome measures-Conserved sequence of DR $\beta$ third allelic hypervariable region, sulphoxidation capacity, rheumatoid factor, and development of radiologically determined bone erosions.

Results-None of the 49 patients had radiological erosions at presentation but 25 developed these by four years. Patients with the conserved class II major histocompatibility complex (third allelic hypervariable of DR $\beta 1$ ) genes associated with rheumatoid arthritis had a relative risk for the development of erosions of 1.9 (95\% confidence interval 0.8 to $4 \cdot 5)$. For poor sulphoxidation the risk was $2.5(1.1$ to 5.6$)$ and for the presence of rheumatoid factor $1.8(0.9$ to $3 \cdot 7)$. Of the 33 patients who had two or three of these risk factors, 24 developed erosions, with a relative risk of $11.6(1.7$ to 78.5$)$ compared with only one of the 16 individuals with no or one risk factor.

Conclusions-This preliminary study shows that by using these stable markers it is possible to make clinically useful predictions of outcome in patients with early symmetrical inflammatory arthritis.

University of Birmingham PO Box 363, Edgbaston, Birmingham B15 2TT

\section{Department of Rheumatology \\ P Emery, senior lecturer and consultant rheumatologist M Salmon, senior research fellow \\ E Tunn, lecturer \\ P A Bacon, professor of \\ rheumatology}

\section{Department of}

Biochemistry

H Bradley, biochemist

$\mathrm{R}$ Waring, senior lecturer

Institute of Molecular Medicine, John Radcliffe Hospital, Oxford EX3 9DU

$\mathrm{P}$ Wordsworth, reader and consultant rheumatologist

Correspondence to:

Dr Emery.

\section{Introduction}

Rheumatoid arthritis is the commonest inflammatory cause of disability.' Predicting the clinical outcome of patients presenting with arthritis is of obvious importance to both patients and physician. Problems in previous studies have been the lack of a defined end point and the use of interrelated disease markers. ${ }^{2}$ We sought to overcome these problems by studying patients early in disease before the development of chronic damage, using for the first time the simultaneous assessment of two genetically determined factors known to be associated with established rheumatoid arthritis. These stable markers are independent of current treatment. The association between rheumatoid arthritis and the first factor, a conserved sequence in the third allelic hypervariable region of the major histocompatibility complex class II Dw1-is well known. ${ }^{3-5}$ The second genetic factor is the presence of defective sulphoxidation. This defect is known to be present in about $75 \%$ of patients with established rheumatoid arthritis, ${ }^{67}$ but the role of this abnormality in predicting radiological erosions has not previously been examined. In this preliminary study $\beta$ chain - that is, DR4/Dw4, DR4/Dw14, and DR1/ we examine whether it might be possible to use these factors in combination with rheumatoid factor to make clinically useful predictions with incremental degrees of sensitivity and specificity in patients presenting with early inflammatory, rheumatoid-like arthritis.

\section{Patients and methods}

The source group comprised 65 consecutive patients with symmetrical polyarthritis (that is, rheumatoidlike) recruited to an early arthritis clinic. Of these, 57 were traced after four years. Complete clinical and genetic information was available on 49 patients, who are the subject of this report. All patients were seen before the start of treatment with a slow acting antirheumatic drug. Full clinical, biochemical, and laboratory assessments were performed at presentation and at three, six, 12, and 48 months. Latex agglutination and Rose-Waaler tests were performed on each visit. Standard radiographs of hands and feet were obtained at presentation and at one and four years. The radiographs were scored independently by two observers for the presence of bone erosions.

To type for the presence of the conserved sequence of DR $\beta$ third allelic hypervariable region DNA was extracted from stored whole blood and DR $\beta$ alleles were amplified with the polymerase chain reaction by using standard techniques. ${ }^{5}$ The product was then hybridised to oligonucleotide probes appropriate for specific sequences. Expression of DR1, DR4, and the DR4 subtypes Dw4 and Dw14 was determined.

Phenotyping for poor sulphoxidation capacity was performed as previously described. ${ }^{8}$ After subjects fasted overnight, $750 \mathrm{mg}$ of S-carboxymethylcysteine was administered and an eight hour urine sample collected. The volume was recorded and an aliquot stored at $-20^{\circ} \mathrm{C}$ until use. The sulphoxidation capacity was expressed as a ratio or sulphoxidation index. This is the percentage of administered dose excreted as sulphate divided by the percentage excreted as sulphoxide. Patients with an index greater than 6 were considered to be poor sulphoxidisers.

Relative risks and confidence intervals were calculated as described previously.

\section{Results}

The details of the 49 patients for whom complete clinical and genetic typing was available are shown in table I. The patients with and without erosions were of similar age and duration of disease. No patient had received corticosteroids at the time of presentation Those who developed erosions had a significantly greater number of painful joints at presentation $(6.4$ (SD 4.2) v 3.1 (4.1), p<0.05), though none of the patients had radiological erosions at presentation. By four years 25 patients had radiological evidence of cortical erosions. Table II shows the sensitivities and specificities of the predictive factors for the patients 
TABLE I-Clinical features at presentation of patients with early symmetrical arthritis

\begin{tabular}{lcc}
\hline & $\begin{array}{c}\text { Patients with } \\
\text { erosions }\end{array}$ & $\begin{array}{c}\text { Patients without } \\
\text { erosions }\end{array}$ \\
\hline No of subjects & 25 & 24 \\
No of women & 14 & 19 \\
Mean (SD) age (years) & $49(13)$ & $45(17)$ \\
Mean (SD) No of painful joints & $6 \cdot 4(4 \cdot 2)^{\star}$ & $3 \cdot 1(4 \cdot 1)^{\star}$ \\
Mean (SD) disease duration (weeks) & $13 \cdot 2(6 \cdot 9)$ & $12 \cdot 6(5 \cdot 8)$ \\
$\begin{array}{l}\text { Mean (SD) early morning stiffness } \\
\text { (minutes) }\end{array}$ & $105(91)$ & $64(83)$ \\
\hline
\end{tabular}

${ }^{\star} \mathrm{p}<0.05$ Mann-Whitney U test.

TABLE II-Predictive value of risk factors for erosions in patients with early symmetrical arthritis

\begin{tabular}{|c|c|c|c|c|c|}
\hline & $\begin{array}{c}\text { No of } \\
\text { patients } \\
\text { with erosions }\end{array}$ & $\begin{array}{c}\text { No of patients } \\
\text { without } \\
\text { erosions }\end{array}$ & $\begin{array}{c}\text { Relative risk } \\
\text { (95\% confidence } \\
\text { interval) }\end{array}$ & Sensitivity & Specificity \\
\hline \multicolumn{6}{|l|}{ Disease epitope } \\
\hline Presence of $3 \mathrm{AHVR}^{\star}$ & 21 & $\begin{array}{r}15 \\
9\end{array}$ & \multirow[t]{2}{*}{$1.9(0 \cdot 8$ to $4 \cdot 5)$} & \multirow[t]{2}{*}{$84 \%$} & \multirow[t]{2}{*}{$38 \%$} \\
\hline \multicolumn{3}{|l|}{ Sulphoxidation } & & & \\
\hline $\begin{array}{l}\text { No with poor sulphoxidation } \\
\text { No with good sulphoxidation }\end{array}$ & $\begin{array}{r}20 \\
5\end{array}$ & $\begin{array}{l}10 \\
14\end{array}$ & $2 \cdot 5(1 \cdot 2$ to $5 \cdot 6)$ & $80 \%$ & $58 \%$ \\
\hline \multicolumn{6}{|l|}{ Rheumatoid factor } \\
\hline $\begin{array}{l}\text { No positive for latex agglutination } \\
\text { No negative for latex agglutination } \\
\text { No with }\end{array}$ & $\begin{array}{r}19 \\
6\end{array}$ & $\begin{array}{r}7 \\
17\end{array}$ & $2 \cdot 8(1 \cdot 3$ to $5 \cdot 8)$ & $76 \%$ & $70 \%$ \\
\hline $\begin{array}{l}\text { No with positive Rose-Waaler test } \\
\text { result } \dagger\end{array}$ & 12 & 4 & \multirow[b]{2}{*}{$1.9(1 \cdot 1$ to $3 \cdot 2)$} & \multirow[b]{2}{*}{$48 \%$} & \multirow[b]{2}{*}{$83 \%$} \\
\hline $\begin{array}{l}\text { No with negative Rose-Waaler test } \\
\text { result }\end{array}$ & 13 & 20 & & & \\
\hline \multicolumn{6}{|l|}{ Genetic risk factors } \\
\hline $\begin{array}{l}\text { Presence of } 2 \text { factors } \\
\text { Presence of } 1 \text { or } 0 \text { factors }\end{array}$ & $\begin{array}{r}16 \\
9\end{array}$ & $\begin{array}{r}4 \\
20\end{array}$ & $2 \cdot 6(1.4$ to $4 \cdot 6)$ & $64 \%$ & $83 \%$ \\
\hline \multicolumn{6}{|l|}{ Genetic risk factors and rheumatoid factor } \\
\hline $\begin{array}{l}\text { No of patients with } 2 \text { or } 3 \text { factors } \\
\text { No of patients with } 1 \text { or } 0 \text { factors }\end{array}$ & $\begin{array}{r}24 \\
1\end{array}$ & $\begin{array}{r}9 \\
15\end{array}$ & $11.6(1.7$ to 78.5$)$ & $96 \%$ & $63 \%$ \\
\hline \multicolumn{6}{|l|}{ No of risk factors present } \\
\hline 3 & $11(92 \%)$ & $\begin{array}{l}1 \\
8\end{array}$ & & & \\
\hline $\begin{array}{l}2 \\
1\end{array}$ & $\begin{array}{c}13(62 \%) \\
1(7 \%)\end{array}$ & $\begin{array}{r}8 \\
13\end{array}$ & & & \\
\hline 0 & 0 & 2 & & & \\
\hline
\end{tabular}

*Third conserved hypervariable regions.

$\nmid$ Positive result from first visit

with and without erosions at four years. The major histocompatibility complex association was the most sensitive predictor of erosions, followed by poor sulphoxidation and then rheumatoid factor. For specificity the order was reversed. If DR4 was substituted for the third allelic hypervariable region then a reduced sensitivity $(72 \%)$ with an increased specificity $(58 \%)$ was obtained. The relative risk for the presence of the two factors was $2 \cdot 6(95 \%$ confidence interval $1 \cdot 4$ to $4 \cdot 6)$ with a sensitivity of $64 \%$ and specificity of $83 \%$. By combining the genetic factors with the presence of rheumatoid factor we could improve the prediction further. For the 16 patients with one or no risk factor only one $(7 \%)$ developed erosions whereas for the 12 with three risk factors $11(92 \%)$ developed erosions. The positive predictive value for the three markers was $74 \%$ with a negative predictive value of $94 \%$

A raised acute phase response provided surprisingly little additional information. For an erythrocyte sedimentation rate $>20 \mathrm{~mm}$ in the first hour the sensitivity was $84 \%$ with a specificity of $46 \%$ (relative risk 2.3 , 0.96 to 5.6 ) whereas for $\mathrm{C}$ reactive protein $>20 \mathrm{mg} / \mathrm{l}$ it was $68 \%$ and $46 \%$ (relative risk $1.3,0.73$ to $2 \cdot 5$ ). The use of erythocyte sedimentation rate as a predictive factor in combination with the others did not improve the sensitivity but resulted in a loss of specificity.

\section{Discussion}

When a patient presents with symmetrical polyarthritis resembling rheumatoid arthritis the most important issue for both patient and clinician is the likely outcome of this disease. Our preliminary study has identified three stable markers which aid the prediction of outcome in early arthritis. The stability of these markers has particular advantages in a disease such as rheumatoid arthritis when the conventional measure of disease severity (the acute phase response) is labile and influenced by corticosteroids, which are commonly administered early in the disease. The three factors identified on the basis of increased relative risk are independent and represent a cumulative risk so that $92 \%$ of all patients with three risk factors developed erosions compared with only $7 \%$ with one or no risk factor. It should be emphasised, however, that these were patients specifically selected by the symmetrical nature of their disease as being at high risk of persistent disease.

The association between rheumatoid arthritis and specific class II major histocompatibility complex alleles has been examined in many cross sectional studies. Rheumatoid arthritis seems to be associated principally with certain subtypes of HLA-DR4namely, Dw4, Dw14, and Dw15-but also with DR1.3.-5 The DR4 subtypes Dw10 and Dw13, in contrast, show no association with rheumatoid arthritis. The molecules associated with rheumatoid arthritis share a highly conserved sequence in the third allelic hypervariable region of the DR $\beta$ chain between amino acids 67 and 74, while those DR4 molecules that are not associated with rheumatoid arthritis have clear differences in this sequence. Prospective evidence that this is indeed the precise focus within the DR locus for association with rheumatoid arthritis was obtained when it was found that DR6/Dw $16^{10}$ and DRw $10^{11}$ (not to be confused with the DR4 subtype Dw10) were also associated with rheumatoid arthritis in certain ethnic groups. Both of these molecules share the conserved third allelic hypervariable region but differ substantially from the DR4 molecule elsewhere.

In white populations most DR4 consists of the Dw4 and Dw1 14 subtypes; Dw10, Dw13, and Dw15 are very rare, though in other ethnic groups the reverse is often true. This has led to the opinion that, in white people at least, DR4 itself is probably a satisfactory marker of the sequence associated with rheumatoid arthritis and little advantage can be gained by subtyping. Conventional DR and Dw typing methods, however, require carefully prepared viable cells, while DNA typing strategies can be performed on samples of whole blood, facilitating population based studies and ultimately routine laboratory analysis. In this study we have presented data by using the conserved third allelic hypervariable region as a marker of this genetic locus, but we have also analysed the same data substituting DR4, which produces a reduced sensitivity of $72 \%$ with a slightly increased specificity of $58 \%$.

Poor sulphoxidation has been studied extensively. ${ }^{78}$ Certain autoimmune diseases, particularly rheumatoid arthritis, are clearly associated with poor sulphoxidation, and patients with this defect are more likely to have persistent symptoms. This is the first occasion that the role of defective sulphoxidation in the development of erosions has been examined. The mechanism by which defective sulphoxidation influences the disease processes is unclear but as this phenotype is a marker for defective cysteine dioxygenase activity the consequent lack of sulphate may well be rate limiting in the repair of glycosaminoglycans in connective tissue. This may mean for a set amount of immunological upset a patient faced with defective sulphoxidation will have greater biochemical and physical damage. The occurrence of radiological erosions may be one manifestation of this.

The predictive value of rheumatoid factor has been examined previously ${ }^{2}$ and for those who are seropositive at presentation it remains the best and certainly the most convenient marker of persistent disease, with a positive result of the Rose-Waaler test the most specific marker for the development of erosions. Only $48 \%$ of patients, however, had positive results at presentation. The value of the other factors is most apparent in predicting outcome for those patients who are seronegative for rheumatoid factor at onset. 
For patients who seem to have rheumatoid arthritis at presentation it is important to identify those who will not progress - that is, not develop erosions. Such patients can be treated symptomatically or given a short course of steroids. This study indicates that patients with fewer than two risk factors fall into this category. The second important group to distinguish are those who will have persistent and erosive disease, for whom early use of a slow acting antirheumatic drug would be appropriate. Patients possessing two or three risk factors are, from the evidence of this study, likely to have this outcome. An additional goal is to identify the small group of patients with a rapidly progressive course of the disease. Fortunately, with current treatment this is a relatively rare outcome and consequently the small number of patients is too few to be identified in a study of this size. The ability to identify such individuals at presentation, however, will become more relevant as specific immunomodulatory treatment becomes available. Large multicentre studies ${ }^{13}$ have been set up to produce the power to identify the predictive factors for such patients and will allow the testing of the results of this preliminary study with a much larger number of patients.

We thank the Arthritis and Rheumatism Council for financial support and the epidemiology research unit, Manchester, for statistical advice.
Harris ED. The clinical features of rheumatoid arthritis. In: Kelly ww Harris ED, Ruddy MD, Sledge CB, eds. Textbook of rheumatology. 3rd ed. Philadelphia: Saunders, 198

2 Van der Heijde DMFM, van Riel PLCM, van Rijswijk MH, van de Putte LBA. Influence of prognostic features on the final outcome in RA. A review of the literature. Semin Arthritis Rheum 1988;17:284-92.

3 Gregersen PK, Shen M, Song QL, Merryman P, Degar S, Seki T, et al. Molecular diversity of HLA-DR4 haplotypes. Proc Natl Acad Sci USA 1986;83:2642.

4 Winchester RJ, Gregersen PK. The molecular basis of susceptibility to rheumatoid arthritis: the conformation equivalence hypothesis. Springer Semin Immunopathol 1988:10:119-39.

5 Wordsworth BP, Lanchbury JSS, Sakkas LI, Welsh KI, Bell JI. HLA-DR subtype frequencies in rheumatoid arthritis indicate that DRBl is the major subtype frequencies in rheumatold arthritis indicate that DRBl is the major
susceptibility locus within the HLA class II region. Proc Natl Acad Sci USA 1989;86:10049.

6 Emery P, Panayi GS, Huston G, Welsh KI, Waring R, Mitchell SC. D-Penicillamine-induced toxicity in rheumatoid arthritis: the role D-Penicillamine-induced toxicity in rheumatoid arthritis: the
sulphoxidation status and HLA-DR3. I Rheumatol 1984;11:626-32.

7 Emery P, Bradley H, Gough A, Arthur V, Jubb R, Waring RH. Increased prevalence of poor sulphoxidation in patients with rheumatoid arthriti Ann Rheum Dis 1992;51:318-20.

8 Mitchell SC, Waring RH, Haley CS, Idle JR, Smith RL. Genetic aspects of the polymodally distributed sulphoxidation of S-carboxymethyl-L-cysteine in man. Br f Clin Pharm 1984;18:507-21.

9 Gardiner M, Altman DG. Statistics with confidence-confidence intervals and statistical guideline. London: BMJ, 1989.

10 Wilkins RF, Nepom GT, Marks J, Nettles JW, Nepom BS. Association of HLA Dw16 with RA in Yakima indians: further evidence for the shared epitope hypothesis. Arthritis Rheum 1991;34:43.

11 Wordsworth BP, Stedeford J, Rosenberg WMC, Bell JI. Limited heterogeneity of the class II contribution to susceptibility to rheumatoid arthritis is suggested by positive associations with HLA-DR4 and DRw10. Br f Rheum suggested by $1990: 30: 178$.

12 Young A, Cox N, Dixie J, James D, Gough A, Gallivan S, et al. Early rheumatoid arthritis study (ERAS). Report of first 506 patients. Arthritis Rheum 1991;34:9 S48;93.

(Accepted 6 October 1992)
Department of Surgery, Charing Cross Hospital, London W6 8RF Christine J Moffatt, clinical nurse specialist

Peter J Franks, lecturer Margaret Oldroyd, research nurse

Roger M Greenhalgh, professor of surgery

Department of Social Policy, Royal Holloway and Bedford New College, University of London, Surrey TW20 0EX

Nick Bosanquet, professor of health policy

Family and Community Services Unit, Riverside District Health Authority, West London Hospital, London W6 7DQ

Pearl Brown, manager,

primary services

Department of Surgery, University Hospital of South Manchester, West Didsbury, Manchester M20 8LR

Charles N McCollum,

professor of surgery

Correspondence to: Mrs Moffatt.

\title{
Community clinics for leg ulcers and impact on healing
}

\author{
Christine J Moffatt, Peter J Franks, Margaret Oldroyd, Nick Bosanquet, Pearl Brown, \\ Roger M Greenhalgh, Charles N McCollum
}

\section{Abstract}

Objective-To evaluate the effectiveness of community clinics for leg ulcers.

Design-All patients with leg ulceration were invited to community clinics that offered treatment developed in a hospital research clinic. Patients without serious arterial disease (Doppler ankle/ brachial index $>0.8$ ) were treated with a high compression bandage of four layers.

Setting-Six community clinics held in health centres in Riverside District Health Authority supported by the Charing Cross vascular surgical service.

Patients-All patients referred to the community services with leg ulceration, irrespective of cause and duration of ulceration.

Main outcome measures-Time to complete healing by the life table method.

Results-550 ulcerated legs were seen in 475 patients of mean (SD) age 73.8 (11.9) years. There were 477 venous ulcers of median size $4.2 \mathrm{~cm}^{2}$ (range $0 \cdot 1-117 \mathrm{~cm}^{2}$ ), 128 being larger than $10 \mathrm{~cm}^{2}$. These ulcers had been present for a median of three months (range one week to 63 years) with 150 present for over one year. Four layer bandaging in the community clinics achieved complete healing in 318 $(69 \%)$ venous ulcers by 12 weeks and $375(83 \%)$ by 24 weeks. There were 56 patients with an ankle/brachial arterial pressure index $<0.8$, indicating arterial disease. The 50 patients with pressure index $<0.8>0.5$ were treated with reduced compression, and $24(56 \%)$ healed by 12 weeks and $31(75 \%)$ by 24 weeks. The figures for overall healing for all leg ulcers were $351 / 550(67 \%)$ at 12 weeks and $417 / 550$ $(81 \%)$ at 24 weeks, compared with only $11 / 51(22 \%)$ at 12 weeks before the community clinics were set up.

Conclusions-Community clinics for venous ulcers offer an effective means of achieving healing in most patients with leg ulcers.

\section{Introduction}

The treatment of leg ulceration has been delegated predominantly to district nurses, with poor healing despite their hard work. Nationally, district nurses spend up to half of their time treating leg ulcers. ' Half the patients are seen more than twice weekly and over a fifth treated daily. Clinical research has generally been of poor quality and the resulting service is uncoordinated and largely ineffective.

Until recently management of ulcers was rarely based on sound scientific principles; instead marketing pressures have influenced the choice of dressings, irrespective of efficacy. ${ }^{23}$ Diagnosis and investigation of these patients have been little better, with few objective attempts to determine the cause of ulceration in each patient.

Various new approaches to the clinical management of these ulcers were developed in a research ulcer clinic in the vascular surgical service at Charing Cross Hospital. These included a four layer compression bandage, which achieved a healing rate of $74 \%$ at 12 weeks in outpatients with venous ulcers and the introduction of pinch skin grafting and venous assessment. ${ }^{+6}$ This service was rapidly overcome by referrals so that only a small proportion of patients could be seen, with most remaining under the care of district nurses.

To determine whether a service based in the community could achieve comparable rates of healing, a network of community clinics was established throughout Riverside District Health Authority, providing easy access for all patients with leg ulcers to the new methods of assessment and treatment. These 